\title{
Assessment of Co-Morbidities and Self Esteem in Obese Population of Urban Slum of Mumbai
}

\author{
Bhuwan Sharma $^{1}$, He mant Mahajan ${ }^{2, *}$, S. R. Suryawans hi ${ }^{1}$, Amit Bhondve ${ }^{1}$ \\ ${ }^{1}$ Department of Community Medicine, TN Medical College, Mumbai, India \\ ${ }^{2}$ Department of Community Medicine, RCSM GMC Kolhapur, India
}

\begin{abstract}
Obesity is perhaps the most prevalent form of malnutrition. As a chronic disease, prevalent in both developed and developing countries, and affecting both children and adults replacing the more traditional public health concerns including under-nutrition. For industrialized countries, it has been suggested that such increase in body weight have been caused primarily by reduced levels of physical activity, rather than by changes in food intake or other factors. The present study was carried out to assess the various co-morbidities associated with obesity and to assess self-esteem score of obese patients in an urban slumof Mu mbai. A descriptive epidemiological study was conducted at Cheetah Camp u rban slum which is a field practice area of Department of Preventive and Social Medicine, TN Medical College, Mumbai, India. Obese and overweight patients above 40 years of age were included in this study. The information was gathered by personal interview using semi-structured questionnaires. Out of 350 subjects 163 (46.57\%) were males. Mean Self-esteem score was 19.47 Patients having high body mass index had poor control over blood pressure and blood sugar. Thus society for elderly should be formed where various life style changes to prevent geriatric problems including obesity and as sociated co-morbidities like diabetes, hypertension, etc. should be encouraged.
\end{abstract}

Keywords Co-morbidities, Obesity, Self-esteem, Urban Slum

\section{Introduction}

We are unanimous in our belief that obesity is a hazard to health and detrimental to well being. It is common enough to constitute one of the most important medical and public health problems of our lifetime, whether we judge importance by shorter expectation of life, increased morbidity or cost to the community in terms of both money and anxiety.

Obesity has reached epidemic proportions in India in the 21 st century, with morbid obesity affecting $5 \%$ of the country's population[1]. India is currently facing a "double burden" of disease, while we continue to deal with the problems of infectious disease and under-nutrition, we are now experiencing a rapid upsurge in non-communicable disease risk factors such as obesity and overweight, particularly in urban settings.

As obesity is a key risk factor in natural history of other chronic and non-communicable disease, the typical time sequence of emergence of chronic disease following the increased prevalence of obesity is important in public health planning. The first adverse effects of obesity to emerge in

* Corresponding author:

hemant.mahajan.84@gmail.com (Hemant Mahajan)

Published online at http://journal.sapub.org/ijpt

Copyright (C) 2012 Scientific \& Academic Publishing. All Rights Reserved population are hypertension, hyperlipidemias and glucose intolerance, while coronary heart disease and the long term complications of diabetes, such as renal failure begin to emerge several years later. It is matter of time before same mortality rates for such diseases will be seen in developing countries as those prevailing 30 years ago in industrialized countries.

Obesity not only affects the individual pathologically but also psychologically. People who are obese are more psychologically affected than non-obese people, particularly those patients who are obese in adolescence. A galaxy of psychological traits appears to result from the obesity related obsessive concern with self image, such passivity, expectation of rejection, and progressive withdrawal. Obesity has an important relationship with psychosocial conditions, such as low self-esteem which can lead to depression[2]. Depression may tend to make obesity self perpetuating.

Obesity has been traditionally considered as a disease of affluence. High prevalence of malnutrition in people belonging to low socio-economic strata in developing countries led to the assumption that obesity will not be a crucial problem in them. Whereas rural population usually has low risk of development of obesity in India[3] their migration to metropolitan cities exposes them to several adverse lifestyle and environmental influences. In cities they usually settle down in urban slums, and take to daily 
wage jobs. Several lifestyle alterations result from this transition: changes from their traditional penurious eating habits, exposure to severe stress, decreased physical activity, and increase in smoking, tobacco chewing and alcohol intake. Unfortunately, this population has not been researched in detail. The present study was carried out to assess self image and co-morbid ities associated with obesity and also to identify the area that needs urgent attention to modify their life style.

\section{Material and Methods}

The study was conducted at Cheetah Camp urban slum which is a field practice area of Department of Preventive and Social Medicine, of TN Medical College, Mumbai, India. This is situated at an eastern suburb of Mumbai which comes under the jurisdiction of $\mathrm{M}$ East Ward of Municipal Corporation of Greater Mumbai. The population of Cheetah Camp consists of people who have migrated from different parts of India, mainly from Uttar Pradesh, Bihar, West Bengal, Madhya Pradesh, Andhra Pradesh and Tamil Nadu. They have migrated to Mumbai in search of job and are now engaged in small scale industries like Zari work, Bag making, Mat weaving, Carpentry, tailoring etc. Most of the men are self employed and women are house wives, maid servants or vegetable vendors. Study population was selected fro mobese patients of age 40 years $\&$ above.

The present commun ity based descriptive epidemiologica 1 study was conducted during the period of October 2011 to December 2011.

Total Population of Study Area $=1,13,000$.

Population $>40$ years $=20,340$ (Applying national demographic parameters)

Prevalence of Obesity $>40$ years in an urban slum of Mumbai $=14 \%[4]$.

Expected number of obese patients in study population $=$ 2,848

Taking $10 \%$ of expected patients $=284.8$, and applying for attrition losses $(20 \%)$

Sample size $(\mathrm{n})=/>350$. So, total 350 obese patients were involved (BMI $>23)$.

Semi structured interview schedule was constructed relevant to the study. This interview schedule was tested by pilot study on 35 obese patients attending geriatric clinic in Urban Health Center. Appropriate changes were done based on pilot study and the interview schedule was finalized. Voluntary consent form was prepared in English, Hindi and Marathi.

By taking, inclusion and exclusion criteria into consideration, total 350 overweight and obese subjects were selected by employing Systemic random sampling method.

The subjects were categorized according to Western Pacific Region of WHO criteria[5] pertaining to obesity (WPRO criteria, 2000) into following groups:
BMI $23-24.99 \mathrm{~kg} / \mathrm{m}^{2}$ as Overweight; BMI $25-29.99$ $\mathrm{Kg} / \mathrm{m}^{2}$ as Obesity I; BMI $\geq 30 \mathrm{Kg} / \mathrm{m}^{2}$ as Obesity II (Morbid Obesity).

Home visits were done between 10.00 am to $4.00 \mathrm{pm}$ on working days.

The information was collected about various socioeconomic factors, family history, addiction, exercise, associated disorders, life style etc. on preformed, pre tested interview schedule by investigator himself. Height, Weight, Blood sugar and Blood pressure were measured by using appropriate technique. Self-esteem analysis was done by administrating Rosenberg Self-esteem Scale[6] according to which patients were classified as having Low $(<15)$, Normal (15-25) and High (>25) Self esteem.

While filling proformas, 30 minutes of health education was given to patients covering following topics:

1) Basic information about Obesity and its associated co-morbidities.

2) Importance of Diet control and regular physical exercise in controlling Obesity.

3) Motivation of the patients to change their life style

\section{Results}

Table 1. Obesity indicat ors in study population

\begin{tabular}{|c|c|c|c|c|c|}
\hline $\begin{array}{c}\text { Obesity } \\
\text { Indicators }\end{array}$ & & $\begin{array}{c}\text { Male } \\
(163)\end{array}$ & $\begin{array}{c}\text { Female } \\
(187)\end{array}$ & $\begin{array}{c}\text { Total } \\
(350)\end{array}$ \\
\hline $\begin{array}{c}\text { Body Mass } \\
\text { Index (BMI) } \\
\text { in Kg/m }\end{array}$ & $\begin{array}{c}\text { Over- } \\
\text { weight }\end{array}$ & $23-24.99$ & 15 & 55 & $\begin{array}{c}70 \\
(20 \%)\end{array}$ \\
\cline { 2 - 6 } & Obese & $>25$ & 148 & 132 & $\begin{array}{c}280 \\
(80 \%)\end{array}$ \\
\hline \multirow{2}{*}{$\begin{array}{c}\text { Waist to Hip } \\
\text { ratio }\end{array}$} & Obese & $\begin{array}{c}\mathrm{M}>0.9 \& \\
\mathrm{~F}>0.8\end{array}$ & 128 & 115 & $\begin{array}{c}243 \\
(69.4 \%)\end{array}$ \\
\cline { 2 - 6 } & $\begin{array}{c}\text { Non- } \\
\text { obese }\end{array}$ & $\begin{array}{c}\mathrm{M} \leqslant 0.9 \& \\
\mathrm{~F} \leqslant 0.8\end{array}$ & 35 & 72 & $\begin{array}{c}107 \\
(30.6 \%)\end{array}$ \\
\hline
\end{tabular}

Table 2. Distribution of patients according to associated co-morbidities

\begin{tabular}{|c|c|}
\hline Associated co-morbidities & Frequency \\
\hline Hypertension (HT) & $61(17.4 \%)$ \\
\hline Diabetes (DM) & $46(13.1 \%)$ \\
\hline DM + HT & $29(8.3 \%)$ \\
\hline Osteoarthritis & $47(13.4 \%)$ \\
\hline Backache & $50(14.3 \%)$ \\
\hline Respiratory Problems & $30(8.6 \%)$ \\
\hline Menstrual Irregularities & $38(10.9 \%)$ \\
\hline
\end{tabular}

Out of 350 subjects 163 (46.57\%) were males, $280(80 \%)$ were obese having Body Mass Index above $25 \mathrm{~kg} / \mathrm{m} 2$. Table 1 show; according to Waist to hip ratio $69.4 \%$ study population were obese.

Table 2 and 3 show; 139 (39.7\%) individual had some kind of associated co-morbidity and 108 (30.9\%) patients had addictions. Hypertension (17.4\%) was the commonest associated co-morbidity followed by Diabetes Mellitus (13.1\%); while alcohol intake (18\%) was the most common type of addiction followed by tobacco chewing (11.4\%). 
Table 3. Distribution of patients according to addictions

\begin{tabular}{|c|c|}
\hline Addictions & Frequency \\
\hline Alcohol & $63(18 \%)$ \\
\hline Tobacco & $40(11.4 \%)$ \\
\hline Smoking & $31(8.9 \%)$ \\
\hline Gutkha & $29(8.3 \%)$ \\
\hline Mawa & $18(5.1 \%)$ \\
\hline Misri Brushing & $21(6 \%)$ \\
\hline
\end{tabular}

Table 4 and 5 reveal that patients having BMI above 25 had poor control over Systolic, Diastolic blood pressure and Blood Sugar. 115 (32.8\%) obese patients had anaemia (i.e. Haemoglobin $(\mathrm{Hb})$ less than $11 \mathrm{gm} \%$, most of them were females. Table 6 shows; 50 (14.3\%) had low self esteem score and significant association was seen between high body mass index (BMI above 25) and low self esteem score. Table 7 reveals patients had high normal Mean Systolic (i.e.
$139 \mathrm{~mm} \mathrm{Hg}$ ), mean Diastolic blood pressure $(89 \mathrm{~mm} \mathrm{Hg}$ ) and Random blood sugar $(140 \mathrm{mg} / \mathrm{dl})$. Thus they were more prone for the development of Hypertension and Diabetes Mellitus (DM).

Table 4. Laboratory examination of subjects

\begin{tabular}{|c|c|c|c|}
\hline \multirow{2}{*}{\multicolumn{2}{|c|}{ Laborat ory Examination }} & \multicolumn{2}{|c|}{ SEX } \\
\hline & & \multirow{2}{*}{$\begin{array}{c}\text { Male } \\
149(42.6 \%)\end{array}$} & \multirow{2}{*}{$\frac{\text { Female }}{179(51.1 \%)}$} \\
\hline Systolic BP in & $<140$ & & \\
\hline $\mathrm{mm} \mathrm{Hg}$ & $\geq 140$ & $14(4 \%)$ & $8(2.3 \%)$ \\
\hline \multirow{2}{*}{$\begin{array}{c}\text { Diastolic BP in } \\
\mathrm{mm} \mathrm{Hg}\end{array}$} & $<90$ & $117(33.4 \%)$ & $171(48.9 \%)$ \\
\hline & $\geq 90$ & $46(13.1 \%)$ & $16(4.6 \%)$ \\
\hline \multirow{2}{*}{$\begin{array}{l}\text { Random Blood } \\
\text { sugar in mg/dl }\end{array}$} & $\leqslant 200$ & $155(44.3 \%)$ & $168(48 \%)$ \\
\hline & $>200$ & $8(2.3 \%)$ & $19(5.4 \%)$ \\
\hline \multirow{2}{*}{$\begin{array}{c}\text { Anaemia }(\mathrm{Hb}< \\
11 \mathrm{gm} \%)\end{array}$} & Yes & $25(7.1 \%)$ & $90(25.7 \%)$ \\
\hline & No & $138(39.4 \%)$ & $97(27.7 \%)$ \\
\hline
\end{tabular}

Table 5. Association of BMI and Blood Pressure and Random Blood Sugar

\begin{tabular}{|c|c|c|c|c|c|}
\hline \multirow{2}{*}{ Systolic B.P. } & \multicolumn{3}{|c|}{ Body Mass Index in $\mathrm{kg} / \mathrm{m}^{2}$} & \multirow[t]{2}{*}{ Total } & \multirow{2}{*}{ Pearson Chi-square test } \\
\hline & & $23-24.99$ & $\geq 25$ & & \\
\hline \multirow{2}{*}{$\leqslant 140 \mathrm{~mm} \mathrm{Hg}$} & $\mathrm{N}$ & 70 & 228 & 298 & \multirow{6}{*}{$\begin{array}{c}\text { Chi-square value- } 26.9 ; \\
\text { Degree of freedom- } 1 \text {; } \\
\text { p-value }<0.01 \text {; } \\
\text { Significant Association }\end{array}$} \\
\hline & $\%$ & $23.5 \%$ & $76.5 \%$ & $100 \%$ & \\
\hline \multirow{2}{*}{$>140 \mathrm{~mm} \mathrm{Hg}$} & $\mathrm{N}$ & 0 & 22 & 22 & \\
\hline & $\%$ & $0.00 \%$ & $100 \%$ & $100 \%$ & \\
\hline \multirow{2}{*}{ Total } & $\mathrm{N}$ & 70 & 280 & 350 & \\
\hline & $\%$ & $20 \%$ & $80 \%$ & $100 \%$ & \\
\hline \multirow{2}{*}{ Diastolic B.P. } & \multicolumn{3}{|c|}{ Body Mass Index in $\mathrm{kg} / \mathrm{m}^{2}$} & & \multirow{2}{*}{ Pearson Chi-square test } \\
\hline & & $23-24.99$ & $\geq 25$ & Total & \\
\hline \multirow{2}{*}{$<90 \mathrm{~mm} \mathrm{Hg}$} & $\mathrm{N}$ & 64 & 224 & 288 & \multirow{6}{*}{$\begin{array}{c}\text { Chi-square value- } 4.3 \text {; } \\
\text { Degree of freedom- } 1 \text {; } \\
\text { p-value - } 0.03 \text {; } \\
\text { Significant Association }\end{array}$} \\
\hline & $\%$ & $22.2 \%$ & $77.8 \%$ & $100 \%$ & \\
\hline \multirow{2}{*}{$\geq 90 \mathrm{~mm} \mathrm{Hg}$} & $\mathrm{N}$ & 6 & 56 & 62 & \\
\hline & $\%$ & $9.7 \% \%$ & $90.3 \%$ & $100 \%$ & \\
\hline \multirow{2}{*}{ Total } & $\mathrm{N}$ & 70 & 280 & 350 & \\
\hline & $\%$ & $20 \%$ & $80 \%$ & $100 \%$ & \\
\hline \multirow{2}{*}{ Random blood sugar } & \multicolumn{3}{|c|}{ Body Mass Index in $\mathrm{kg} / \mathrm{m}^{2}$} & \multirow{2}{*}{ Total } & \multirow{2}{*}{ Pearson's Chi-squaretest } \\
\hline & & $23-24.99$ & $\geq 25$ & & \\
\hline \multirow{2}{*}{$\leq 200 \mathrm{mg} \%$} & $\mathrm{~N}$ & 70 & 222 & 292 & \multirow{6}{*}{$\begin{array}{c}\text { Chi-square value- } 15.9 ; \\
\text { Degree of freedom-1; } \\
\text { p-value }<0.01 \text {; } \\
\text { Significant Association }\end{array}$} \\
\hline & $\%$ & $24.64 \%$ & $75.36 \%$ & $100 \%$ & \\
\hline \multirow{2}{*}{$>200 \mathrm{mg} \%$} & $\mathrm{~N}$ & 0 & 58 & 58 & \\
\hline & $\%$ & $0.00 \%$ & $100 \%$ & $100 \%$ & \\
\hline \multirow{2}{*}{ Total } & $\mathrm{N}$ & 70 & 280 & 350 & \\
\hline & $\%$ & $20 \%$ & $80 \%$ & $100 \%$ & \\
\hline
\end{tabular}

Table 6. Self esteem evaluation in study population

\begin{tabular}{|c|c|c|c|c|c|}
\hline \multirow{2}{*}{ Self-Es teem Score } & \multicolumn{5}{|c|}{ SEX } \\
\hline & \multicolumn{3}{|c|}{ Males } & \multicolumn{2}{|r|}{ Females } \\
\hline Low self esteem $(<\mathbf{1 5})$ & \multicolumn{3}{|c|}{$15(4.3 \%)$} & \multicolumn{2}{|r|}{$35(10 \%)$} \\
\hline Normal self est eem (15-25) & \multicolumn{3}{|c|}{$135(38.6 \%)$} & \multicolumn{2}{|r|}{$152(43.4 \%)$} \\
\hline High self esteem $(>\mathbf{2 5})$ & \multicolumn{3}{|c|}{$13(3.7 \%)$} & \multicolumn{2}{|r|}{$0(0 \%)$} \\
\hline \multirow{2}{*}{ Self Esteem score } & \multicolumn{3}{|c|}{ Body Mass Index in $\mathrm{kg} / \mathrm{m}^{2}$} & \multirow{2}{*}{ Total } & \multirow{2}{*}{ Pearson Chi-square test } \\
\hline & & $23-24.99$ & $\geq 25$ & & \\
\hline \multirow{2}{*}{ Low } & $\mathrm{N}$ & 9 & 41 & 50 & \multirow{8}{*}{$\begin{array}{c}\text { Chi-square value- } 20.5 ; \\
\text { Degree of freedom- } 2 ; \\
\text { p-value }<0.01\end{array}$} \\
\hline & $\%$ & $18.00 \%$ & $82.00 \%$ & $100 \%$ & \\
\hline \multirow{2}{*}{ Normal } & $\mathrm{N}$ & 52 & 235 & 287 & \\
\hline & $\%$ & $18.05 \%$ & $80.45 \%$ & $100 \%$ & \\
\hline \multirow{2}{*}{ High } & $\mathrm{N}$ & 9 & 4 & 13 & \\
\hline & $\%$ & $71.43 \%$ & $28.57 \%$ & $100 \%$ & \\
\hline \multirow{2}{*}{ Total } & $\mathrm{N}$ & 70 & 280 & 350 & \\
\hline & $\%$ & $20 \%$ & $80 \%$ & $100 \%$ & \\
\hline
\end{tabular}


Table 7. Descriptive statistics

\begin{tabular}{|c|c|c|c|c|}
\hline Parameters & $\mathrm{N}$ & Mean & Standard Deviation & Std. Error of Mean \\
\hline BMI (Body Mass Index in $\mathrm{kg} / \mathrm{m}^{2}$ ) & 350 & 26.5 & 2.10 & 0.16 \\
\hline Waist-Hip Ratio & 350 & 0.89 & 0.16 & 0.01 \\
\hline Systolic B.P in mm Hg & 350 & 138.5 & 12.42 & 0.94 \\
\hline Diastolic B.P. in mm Hg & 350 & 88.89 & 10.48 & 0.97 \\
\hline Haemoglobin (gm \%) & 350 & 11.25 & 2.05 & 0.16 \\
\hline Random Blood sugar (mg \%) & 350 & 138.8 & 45.30 & 3.43 \\
\hline Self Esteem Score & 350 & 19.47 & 3.94 & 0.29 \\
\hline
\end{tabular}

\section{Disscussion}

The present community based descriptive epidemiologica 1 study was conducted at an urban slum in Mumbai, India. It was conducted during the period of October 2011 to December 2011 by selecting 350 overweight and obese populations by employing systematic random sampling method.

Out of 350 subjects $163(46.57 \%)$ were males and 187 $(53.43 \%)$ were females. Obesity was found to be more in the females as compared to the males in age group 40-60 years. This finding is in concordance with the Framingham, USA study[7] which states that, men were found to gain most weight between the ages of 29 and 35 years, while wo men gain most between 45 and 49 years of age. After using the WPRO-2000criteria, we found that $80 \%$ were obese and $20 \%$ patients were overweight.

By comparing above data with the Waist-Hip ratios of the study population, we found that $(69.4 \%)$ were obese while $20(30.6 \%)$ patients were overweight. The contrast in above data suggest that waist-hip ratio criteria also needs to be modified in accordance with the new BMI cut offs, as majority of the subjects who came under overweight category by new BMI cut off limits were classified as non-obese by waist-hip ratio standards.

In our study $139(39.7 \%)$ individual had some kind of associated co-morbidity and 108 (30.9\%) patients had addictions. Hypertension (17.4\%) was the commonest associated co-morbidity followed by Diabetes Mellitus (13.1\%); while alcohol intake (18\%) was the most common type of addiction followed by tobacco chewing (11.4\%). Though Diabetes[8], Hypertension[9], Osteoarthritis[10], and Menstrual Irregularities[10], are more common in age group 40-60 years, but obesity also has a positive association with these conditions and it increases either their severity or cause their premature development.

On inquiring about the family history of the obese subjects, 36 (10.28\%) patients had family history. The other condition with a positive family history was breast carcinoma, with a total of $5(1.43 \%)$ subjects out of total 350 confirming its presence in their family line. Though obesity has a genetic predisposition as shown by Kolata et al[11] but in our study the number of obese individuals with a positive family history was very low i.e. on ly $36(10.28 \%)$ subjects. This can be explained as the area of our study is an urban slum in which the main problem was malnutrition since ages and obesity was introduced into this population only recently, so most of the obese subjects were obese due to their faulty lifestyle and other associated conditions rather than genetic factors.

The association between obesity and hypertension has been extensively documented by several studies and specifically from the Framingham Study and the National Health and Nutrition Examination Survey[12-15]. In general, obesity and hypertension both are predictors of ACVD (Acute Coronary Vascular Disease), obese people are more prone to hypertension, and most hypertensive patients are obese. Obesity and weight gain are predictors of hypertension independently from the age of onset of obesity; moreover, weight loss is associated with a reduction of blood pressure[16].

In our study patients having BMI above $25 \mathrm{~kg} / \mathrm{m}^{2}$ had poor control over blood pressure. Though only $22(6.3 \%)$ patients had blood pressure above $140 \mathrm{~mm}$ of $\mathrm{Hg}$, mean Systolic and Diastolic blood pressure were towards high normal side. They were more prone for the development of hypertension. On comparing the results of our study with various studies across the globe, we found a substantial amount of evidence supporting our findings. The study done by Elley et al. stated that Regular exercise improves blood flow and helps to reduce the blood pressure[17].

In our study patients having higher body mass index had poor control over random blood sugar. Mean Random Blood sugar was $138.8 \mathrm{mg} / \mathrm{dl}$ which was also towards higher normal side. All the patients having Random Blood Sugar above $200 \mathrm{mg} / \mathrm{dl}$ had body mass index above $25 \mathrm{~kg} / \mathrm{m}^{2}$. Obesity confers a minimum 3- to 10-fold risk of type 2 diabetes [8] and it is estimated that type 2 diabetes risk could be reduced by $50-75 \%$ by control of obesity[18]. Weight loss associated with the onset of diabetes $[19,20]$ means that the association of obesity with type 2 diabetes prevalence is generally weaker than its association with incidence. For example, in an Israeli study, the main determinant of the incidence of type 2 diabetes over a 10-year study period was the BMI at baseline, rather than the BMI at follow-up when glucose tolerance was measured[21]. In a study of Pima Indians baseline BMI was also strongly related to the incidence of type 2 diabetes but there was little association between diabetes prevalence and concurrent obesity[22]. In a small subgroup of subjects of that study with BMI data 
from 4 years before diagnosis to 2 years after, there was a clear pattern of weight gain preceding diagnosis. Meta analys is study done by Boule et al[23] reveals that, exercise (aerobic) reduce $\mathrm{HbA} 1 \mathrm{c}$ to $0.66 \%$ independent of change in body weight in people with Diabetes. In a prospective cohort study done by Wei et al[24] and Church et al[25] reveal that people with Type 2 Diabetes having higher physical activity level, aerobic exercise like walking and resistance exercise like weight lifting predicted lower long term morbidity and mortality and increased insulin sensitivity.

Review of various literatures showed that obesity does have a negative impact on the self esteem of an individual, which can lead to depression[26]. In our study we found out that a substantial a mount of obese subjects $50(14.3 \%)$ were suffering from low self esteem. The prevalence of low self esteem and depressive states are generally more common in females and our study is in affirmation with this fact as majority $(70 \%)$ of subjects with low self esteem were females.

High levels of obesity dents the self esteem of an individual, as shown by the findings of our study in which majority $(82 \%)$ of the subjects with low self esteem scores were found to be obese while most $(71.43 \% \%)$ subjects who were having high self esteem scores have BMI levels less than $25 \mathrm{Kg} / \mathrm{m}^{2}$. While there is a relative paucity of supporting data, there are several potential mechanisms through which obesity could contribute to the development of depression. The societal stigma associated with obesity may have a negative impact on body-image, self-esteem, and social interactions, which could contribute to the development of depression[26]. Additionally, obesity is associated with higher risk of health problems and bodily pain, which could potentiate depressive symptoms.[27-30]

\section{RECOMMENDATIONS}

People have to be educated through mass media on Obesity and its risk factors. The health workers have to play part by educating the people and also themselves being an example in avoiding the risk factors for obesity like consumption of food having high calories, alcohol etc. People have to be educated on the importance of regular physical exercises and have to be encouraged to do the same.

Physical exercise can play a significant role in improving BMI and therefore associated co-morbidities like Hypertension and Diabetes. It also helps in improving the Self-esteem of obese individuals.

\section{REFERENCES}

[1] "India facing obesity epidemic: experts". The Hindu, 2007-10-12. Available at: http://hindu.com./2007/10/12/ stories/2007101260940600.htm

[2] Puhl RM, Heuer CA. The stigma of obesity: a review and update. Obesity (Silver Spring) 2009; 17:941-964.

[3] Gupta OP, Joshi MH, Dave SK. Prevalence of diabetes in India. Adv Metab Disord, 1978; 9: 147-165.

[4] A Misra, RM Pandey, JR Devi, R Sharma, NK. 'High prevalence of diabetes, obesity and dyslipidaemia in urban slum population in northern India'. Int J Obesity, 2001 Nov; 25 (11):1722-9.

[5] "The Asia-Pacific Perspective: Redefining Obesity and its Treatment"--Measurement of Obesity. Page No. 18, Available at-www.scribd.com/doc/33508685/Obesity-Guidelines-for-A sia-Pacific

[6] Rosenberg, M. (1965). Society and the adolescent self-image. Princeton, NJ: Princeton University Press. Available at: www.y orku.ca/rokada/p sy ctest/rosenbrg.doc

[7] Poirier P. Giles TD. Brav GA. et al. "Obesity and cardiovascular disease: pathophysiology, evaluation, and effect of weight loss". Arterioscler. Thromb. Vasc. Biol., 2006; 26 (5): 968-76.

[8] Zimmet P, Alberti K. Leptin: Is it important in diabetes? Diabet Med 1996; 13: 501—503.

[9] Ashish Aneia. Fadi El-Atat. Samv I. McFarlane and James R. Sowers: "Recent Progress in Hormone Research", 2004:59:169-205

[10] Jeffrey S. Flier, Eleftheria Maratos-Flier: Obesity. HARRISON'S Principles of Internal Medicine. The McGraw-Hill Companies, Inc. $16^{\text {th }}$ Edition 2005; 64: 422-429.

[11] Kolata.Gina (2007). Rethinking thin: The new science of weight loss - and the myths and realities of dieting. Picador. pp. 122.

[12] Wilson PW. Established risk factors and coronary artery disease: the Framingham Study. Am J Hypertens 1994; 7: $7 \mathrm{~S}-12 \mathrm{~S}$.

[13] Sundquist J, Winkleby MA. Cardiovascular risk factors in Mexican American adults: a transcultural analysis of NHANES III, 1988-1994. Am J Public Health 1999; 89: $723-730$.

[14] Gillum RF, Mussolino ME, Madans JH. Body fat distribution and hypertension incidence in women and men. The NHANES I Epidemiologic Follow-up Study. Int J Obes Relat Metab Disord 1998; 22: $127-134$.

[15] Ettinger WH, Davis MA, Neuhaus JM, Mallon KP. Longterm physical functioning in persons with knee osteoarthritis from NHANES. I: Effects of comorbid medical conditions. J Clin Epidemiol 1994; 47: 809—815.

[16] Modan M, Halkin H. Hyperinsulinemia or increased sympathetic drive as links for obesity and hypertension. Diabetes Care 1991; 14: 470— 487.

[17] Elley CR, Arroll B (2002). "Review: aerobic exercise reduces systolic and diastolic blood pressure in adults". ACP J. Club 137 (3): 109.

[18] Manson J, Spelsberg A. Primary prevention of non-insulindependent diabetes mellitus. Am J Prev Med 1994; 10: $172-184$ 
[19] Knowler W, Pettitt D, Saad M, Charles M, Nelson R, Howard B. Obesity in the Pima Indians: its magnitude and relationship with diabetes. Am J Clin Nutr 1991; 53: 1543S-1551S

[20] Sicree R, Zimmet P, King H, Coventry J. Weight change amongst Nauruans over 6.5 years extent, and association with glucose intolerance. Diabetes Res Clin Pract 1987; 3: $327-336$.

[21] Modan M, Karasik A, Halkin H, et al. Effect of past and concurrent body mass index on prevalence of glucose intolerance and type 2 (non-insulin dependent) diabetes and on insulin response. The Israeli study of glu cose intolerance, obesity and hypertension. Diabetologia 1986; 29 : 82-89

[22] Knowler W, Pettitt D, Savage P, Bennett P. Diabetes incidence in Pima Indians: contributions of obesity and parental diabetes. Am J Epidemiol 1981; 113: 144-156.

[23] Boule MG, Haddad E, Kenny GP, Wells GA, Sigal RJ. Effects of exercise on gly cemic control and body mass in type 2 diabetes mellitus: A Meta analysis of controlled clinical trials. JAMA 2001;286:1218-27.

[24] Wei M, Gibbons LW, Kampert JB, Nichman MZ, Blair SN. Low cardio-respiratory fitness and physical activities as predictors of mortality in men with type 2 diabetes. Ann Intern Med 2000;132:605-11.

[25] Church TS, Cheng YJ, Earnest CP, Barlow CE, Gibbons LW, Priest EL, et al. Exercise capacity and body composition as predictor of mortality among men with diabetes. Diabetes Care 2004;27:83-8.

[26] Puhl RM, Heuer CA. The stigma of obesity: a review and update. Obesity (Silver Spring) 2009; 17:941-964.

[27] Janke EA, Collins A, Kozak AT. Overview of the relationship between pain and obesity: What do we know? Where do we go next? J Rehabil Res Dev 2007; 44:245-262.

[28] Rejeski WJ, Ip EH, Marsh AP, Zhang Q, Miller ME. Obesity influences transitional states of disability in older adults with knee pain. Arch Phys Med Rehabil 2008; 89:2102-2107.

[29] Verbrugge LM, Gates DM, Ike RW. Risk factors for disability among U.S. adults with arthritis. J Clin Epidemiol 1991; 44:167-182.

[30] Wurtman JJ. Depression and weight gain: the serotonin connection. J Affect Disord 1993; 29:183-192. 